PSICOLOGIA Vol: XI No 21993

\title{
EL APRENDIZAJE Y LA MEMORIA
}

Luis Trelles ${ }^{1}$

El hipocampo es la región cerebral donde ocurren los mecanismos biológicos que se hallan a la base de la memoria explícita. Es decir, de aquella forma de apiendizaje restituible por el lenguaje, como los datos biográficos o los conocimientos escolares o universitarios. A la luz de los hallazgos experimentales más recientes, el autor propone una explicación de la función hipocámpica relativa al aprendizaje.
The hippocampus is the brain region where takes place the biological mechanisms of explicit memory. Explicit memory refers to the type of learning restorable through language, such as biographic facts or academic knowledge. Recent experimental findings have enlarged our comprehension about hippocampal function. Based on them, the author suggests a hypothesis about the biological basis of learning.

1. Es Profesor Principal de la Pontificia Universidad Catolica del Perú y de la Universidad Peruana Cayetano Heredia. Estudió medicina en la Universidad de París y en la Universidad Cayetano Heredia. Se especializó en Neurología en Europa, primero en el Instituto Born Bunge de Amberes (Bélgica) y luego en el Hospital de la Salpetrière (Universidad de París VI-Francia) con los Profesores François Lhermitte y Paul Castaigne. Actualmente es Director de Investigaciones del Instituto Nacional de Ciencias Neurológicas, del que fué Director. Es vice-presidente de la Sociedad Peruana de Neurología y miembro correspondiente de la Sociedad Francesa de Neurologfa, así como de otras sociedades nacionales e internacionales. 

Llamamos aprendizaje a la aptitud para adquirir nuevos conocimientos y memoria a la capacidad de almacenarlos y de restituirlos tiempo después (Kandel y Hawkins, 1992). El aprendizaje requiere de una serie de funciones neurológicas además de la memoria, por ejemplo, la percepción, la atención y la motivación.

Las primeras evidencias que la memoria constituía una función propia del cerebro diferente de la percepción, el lenguaje, el movimiento y la atención surgió de las experiencias de estimulación del gran neurocirujano Wilder G. Penfield, quien en la década dél 40 realizó una serie de estudios que consistían en estimular la corteza cerebral de personas operadas con anestesia local. Pudo asi describir en el hombre los homúnculos sensitivo y motor, así como las áreas visuales y auditivas, pero lo importante para el tema que tratamos consiste en que ocasionalmente al estimular una región cerebral la persóna recordaba una experiencia previa. Los recuerdos eran evocados casi invariablemente por estimulación del lóbulo temporal.

Poco tiempo después William B. Scoville vió a un paciente que sufría de una epilepsia intratable médicamente. Habiéndosele encontrado un foco epiléptico en ambas regiones mediales de los lóbulos temporales decidió removerlas. Al despertarse de la operación, el enfermo conocido como H.M., había perdido la capacidad de adquirir nuevos conocimientos y había olvidado parte de sus vivencias ocurridas antes de la operación (amnesia retrógrada parcial). Esta incapacidad de aprender se asociaba a una atención normal, una memoria a corto plazo ("short term memory") también nortmal y a una inteligencia y razonamiento normalès. Brenda Milner, que estudfó durante largos años al paciente, describe su comportamiento amnésico de la siguiente manera: "Aunque lo conozco desde hace mucho tiempo (varias décadas) y tengo con él una relación muy estrechä, durante sư último cumpleaños que pasamos jüntos H.M. me confesó que no recuerda quien soy yo, a pesar que racionalmente acepta que soy la psicóloga que lo ha tratado durante tantos años".

Los estudios de Brenda Milner en éste y otros enfermos similares han puesto en evidencia que el hipocampo es una región esencial para una forma particular 
de aprendizaje: el llamado aprendizaje explícito o declarativo, es decir aquella forma de aprendizaje conciente que puede ser restituido verbalmente, como por ejemplo: la fecha de mi nacimiento o los conocimientos que adquirí en la escuela o en la universidad. Aquellas formas de aprendizaje, representadas por aprendizajes motores (como montar bicicleta, jugar al tenis, correr tabla, etc.) permanecen intactos en estos pacientes. A esta forma de aprendizaje, no restituible por el lenguaje, se la llama aprendizaje implícito o no declarativo. Los mecanismos responsables del aprendizaje implícito son menos conocidos que los que participan en el aprendizaje explícito. Señalemos únicamente que el cerebelo desempeña muy probablemente un rol importante en esta forma de aprendizaje arcaico.

En lo que se refiere a la memoria explícita se supone, en la actualidad, que las formaciones hipocámpicas almacenan la memoria a largo plazo, por semanas y luego la transfieren progresivamente a otras regiones de la corteza donde los recuerdos son guardadas definitivamente o hasta que se borran. Estas zonas corticales han sido llamadas por Damazio (1992) "regiones de convergencia". Aunque su localización exacta no se conoce se hallan situadas muy probablemente en el neocortex como lo prueba el hecho que las trazas mnesicas desaparecen cuando se produce una destrucción masiva de la corteza cerebral, como ocurre en la enfermedad de Alzheimer. Los trabajos de Squire y Zola-Morgan (1991) en el mono han permitidó precisar las estructuras del lóbulo temporal que se hayan implicadas en el aprendizaje explícito. En magistrales estudios, que combinan la experimentación comportamental mnésica con destrucciones selectivas de las diferentes regiones mediales del lóbulo temporal, han demostrado que las áreas directamente implicadas en la memoria son:
1) El hipocampo
2) El área entorrinal (área 28).
3) El área perirrinal (áreas 35 y 36)
4) El cortex parahipocámpico (áreas TF Y TH)

Es muy importante señalar que la conexiones de éstas áreas son intrínsecas y extrínsecas. Las primeras están representadas por las conexiones que las relacionan entre sí. Las segundas, por las que establecen con otras regiones del cerebro. En lo que se refiere a las conexiones intrínsecas es importante recordar que en la actualidad el término de hipocampo se usa para designar al cuerno de Amón (o hipocampo propiamente dicho), al gyrus dentado, al subículo y al área entorrinal (área 28). Por otro lado vale la pena precisar que el cuerno de Amón se divide en cuatro sectores CA1, CA2, CA3, CA4. Sin entrar en detalles hay que saber que el gyro dentado (Figura 1) recibe la vía perforante proveniente del área 28 y que proyecta sobre las dendritas apicales de la células piramidales 


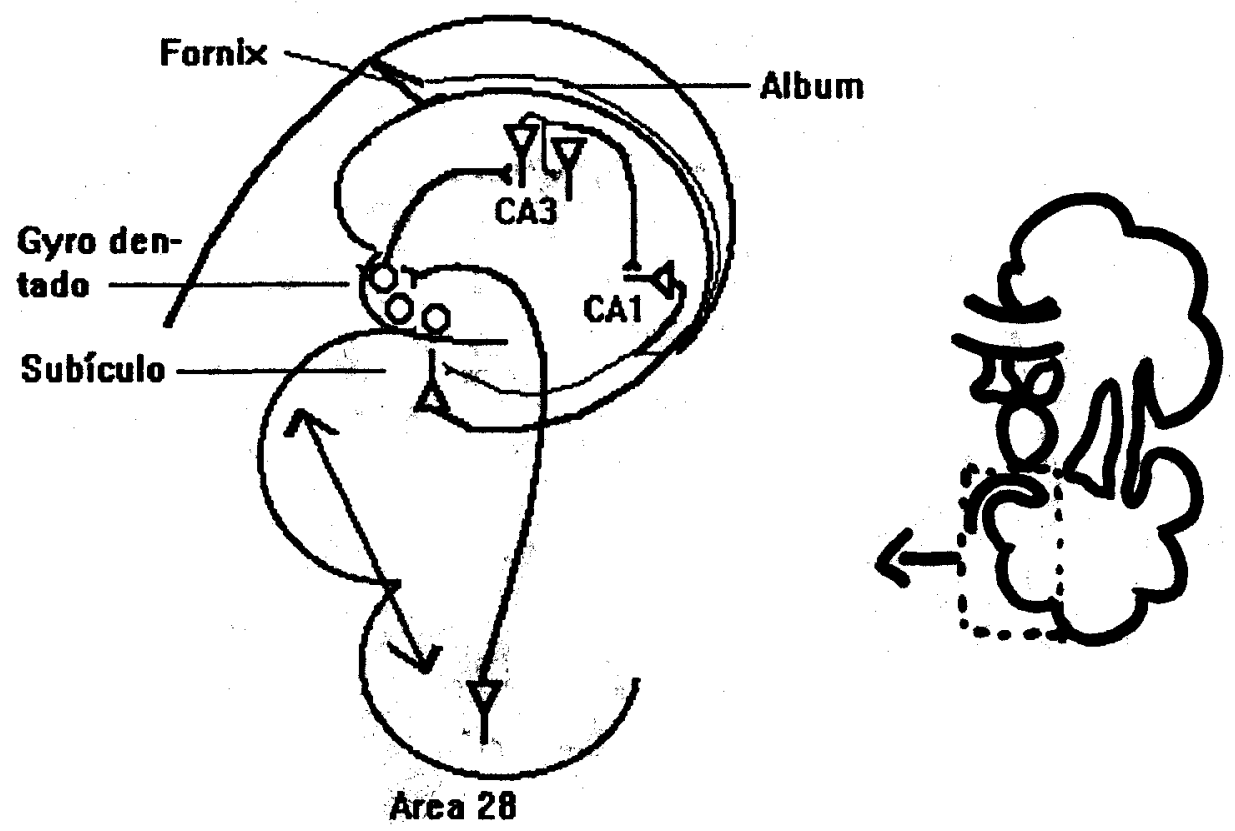

Figura 1

Conexiones intrínsecas de la formación hipocámpica, que está constituida por el cuemo de Amon, el gyrus dentado, el subículo y el área 28 o entorrinal. El área 28 y el subículo están conectados entre sí. El área 28 envía un fascículo al gyrus dentado (GD), llamado vía perforante (VP). Las células del GD envían una proyección a la región CA3 del cuerno de Amon. Las células de esta región se conectan entre si por una colateral de su axón y proyectan sobre las células del sector CA1 del cuerno de Amon. Las células de CA1 proyectan al subículo y a través del fornix a los núcleos septales. Por su lado el subículo proyecta al diencéfalo (cuerpos mamilares) por medio del fornix. Las sinapsis de las regiones CA3, CA1 y del gyrus dentado tienen la propiedad de establecer un LTP o una LTD y por lo tanto establecer redes neuronales modificables.

del área CA3 a través de las fibras musgosas. El axón de las células piramidales del sector CA3 envía dós colaterales: una que se termina en otras células piramidales del sector CA3 y la colateral de Schaffer, que se termina en las dendritas apicales de las células piramidales del sector CA1. Todas estas sinapsis son glutamatérgicas y se establecen sobre dos receptores distintos: el receptor NMDA y un receptor no NMDA. Por otro lado, el área entorrinal proyecta a los sectores CA1, CA2 y al subículo. CAl envía fibras al subículo y al área entorrinal; por su lado el subículo tiene eferentes sobre el áréa entorrinal (área 28): En el cuerno de Amón, al lado de las células piramidales, existen otros tipos de células. Uno de ellos estaría representado por neuronas inhibidoras Gabaérgicas.

En lo que se refiere a sus conexiones extrínsecas, (Figura 2) la formación hipocámpica establece conexiones con casi todo el neocortex y con estructuras 


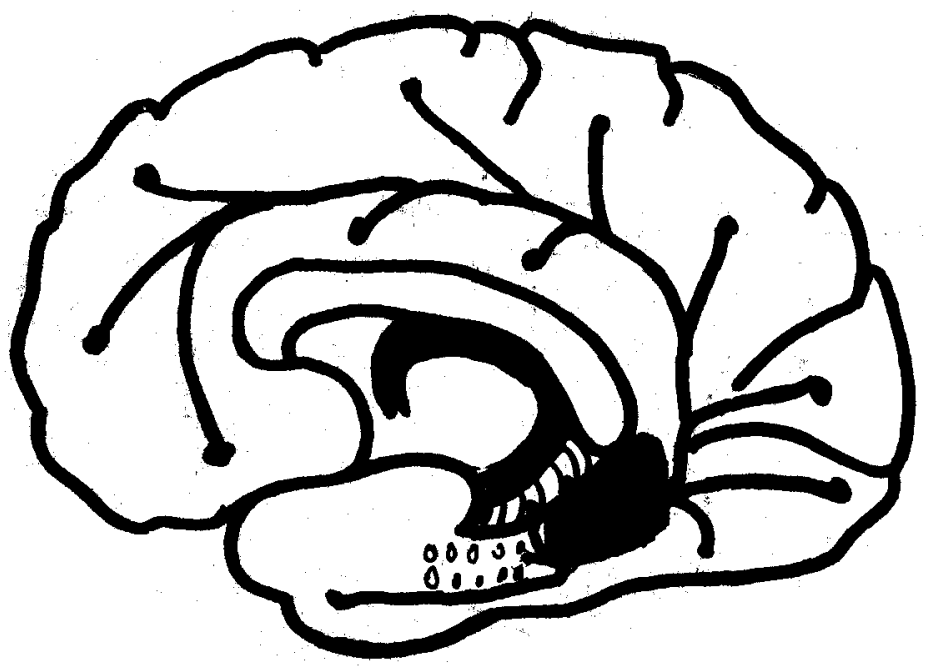

Figura 2

Conexiones extrínsecas del hipocampo: formación hipocámpica: áreas parahipocámpicas (TH y TF): áreas perirrinales: fornix. La formación hipocámpica tiene conexiones en los dos sentidos (aferentes y eferentes) con toda la corteza cerebral tanto de la cara lateral como de la cara interna del cerebro. Estas conexiones se hacen directamente por medio del subículo y del área 28 o indirectamente por medio de las áreas parahipocámpicas o perirrinales. El subículo proyecta por medio del fornix al diencéfalo (núcleos mamilares y tálamo).

subcorticales. Estas conexiones son en las dos direcciones; del neocortex hacia el hipocampo y de este hacia el neocortex. Las conexiones corticales son directas e indirectas. En efecto se hacen en parte por intermedio de las áreas perririnales (35 y 36) y parahipocámpicas (TH Y TF) y en parte directamente. Sea como fuere y para no cansar al lector podemos resumirlas de la siguiente manera: el área 28 y el subículo están conectadas en los dos sentidos con las áreas uni y plurimodales de la corteza prefrontal, frontal, parietal, occipital, temporal e insular. El área entorrinal a su vez proyecta al giro dentado y al cuerno de Amón. La formación hipocámpica no sólo se halla en la posibilidad de hacer sentir sus efectos sobre todo el neocortex (por medio de las proyecciones entorrino subículo corticales), sino que también tiene una potente proyección hacia el diencéfalo por el fornix. En efecto, a partir del subículo el hipocampo proyecta por medio del trígono hacia los cuerpos mamilares y el núcleo anterior del tálamo. Por último, axones de células piramidales de CA1 se incorporan al fornix y se terminan en los núcleos septales. 
Las neuronas hipocámpicas están dotadas de propiedades plásticas sorprendentes. En 1973, Timothy Bliss y Terje Lomo, mientras trabajaba en el laboratorio de Per Andersen en Oslo, encontraron que las neuronas hipocámpicas son capaces de establecer entre si dos tipos de fenómenos sinápticos a los que se ha atribuido un rol importante en el aprendizaje: la potenciación a largo plazo (LTP) y la depresión a largo plazo (LDT). La primera consiste en un refuerzo de la conexión sináptica entre dos neuronas, lo que fortalece la conexión entre ellas y determina la formación de una comunicación privilegiada o circuito, favoreciendo el pasaje de la información de una a otra. De esta manera se crean las condiciones necesarias para la codificación mnésica que, según la teoría ampliamente aceptada de HEBB, se realiza en circuitos neuronales establecidos y organizados durante el aprendizaje. La formación de un circuito se llevaría a cabo por el refuerzo de una sinapsis que privilegia la conexión entre dos neuronas con detrimento de las conexiones que esas mismas neuronas tienen con otras células. La LTP es pues el fenómeno sináptico que puede explicar la teoría de HEBB. La LTD es el fenómeno inverso que haria desaparecer una LTP permitiendo el olvido o el borramiento del circuito a nivel hipocámpico.

La LTP es un mecanismo sináptico que consiste en el reforzamiento de la trasmisión sináptica luego de una estimulación aferente a una frecuencia alta y de algunos milisegundos (Barinaga, 1991; Zalutsky y Nicoll, 1990; Kandel, 1992). En efecto, si estimulamos una fibra presináptica durante algunos milisengundos y con una frecuencia elevada $(1000 \mathrm{~Hz}$, por ejemplo) obtenemos un reforzamiento de la conexión que consiste en que al estimular nuevamente la misma fibra presináptica se obtiene una respuesta mayor que antes de la estimulación, en el elemento postsináptico. Este reforzamiento dura largo tiempo (desde minutos hasta semanas). A nivel bioeléctrico se traduce por un aumento de la amplitud del potencial post-sináptico de excitación. De esta manera, el elemento post-sináptico de la sinapsis reforzada por la LTP, responde con mayor intensidad cada vez que es estimulado por el neurotrasmisor secretado por el elemento presináptico. Es importante recalcar que este reforzamiento de la transmisión sináptica puede deberse a cambios en la porción presináptica (es decir, la célula que envía la señal) o en la porción postsináptica (es decir, la célula que recibe la señal). En otras palabras; la LTP puede originarse en una mayor cantidad de quantas de neurotransmisor liberado o en una mayor sensibilidad del receptor a la misma cantidad de neurotransmisor. Hasta hace poco la segunda posibilidad era la más aceptada y se habían aportado argumentos experimentales serios a su favor. Recientemente (Barinaga, 1991) se han descrito hallazgos experimentales que se interpretan como si la LTP se debería a un cambio presináptico que llevaría a una mayor liberación de quantas de neurotransmisor. A esta conclusión han llegado Tsien y Stevens (Barinaga, 1991) luego de un conteo del número de 
quanta de neurotransmisor liberados, que demostró su aumento en las sinapsis con LTP.

En realidad todo apunta a pensar que varios mecanismos (pre y postsinápticos) conducen a LTP. La LTP ha sido estudiada fundamentalmente en el hipocampo donde es más pronunciada, lo que está de acuerdo con el papel primordial que esta estructura juega en el aprendizaje. Se ha encontrado que por lo menos se produce en dos lugares: en las neuronas piramidales de la región CA1 y en las sinapsis que establecen las fibras musgosas (fibras asociativas comisurales controlaterales) sobre las neuronas piramidales del sector CA3. En ambos lugares está relacionada con la actividad del receptor NMDA de glutamato. La más estudiada es la LTP que se produce en las células piramidales del sector CA1 del hipocampo. El argumento más importante para atribuir la inducción de la LTP al receptor NMDA se halla en que el 2-amino-5-fosfonopentanoato (AP5), un antagonista del receptor NMDA, bloquea la inducción de la LTP. La cadena de eventos que llevaría a la producción de una LTP sería la siguiente: Para que el receptor NMDA se abra y deje entrar iones caloio dos fenómenos deben coincidir (Figura 3). Primero, que se produzca una despolarización de la neurona que permita remover el $\mathrm{Mg}$ del receptor NMDA, pues durante el reposo el magnesio se halla unido al receptor bloqueándo. Segundo, que el glutamato excite el receptor NMDA. Es, probablemente, por esta razón que los axones glutamatérgicos se bifurcan y hacen contacto con dos receptores postsinápticos: receptores NMDA y receptores no NMDA (KA/AMPA). La estimulación presináptica determina la despolarización postsináptica a nivel del receptor KA/AMPA, lo que remueve el $\mathrm{Mg}+$ del receptor NMDA. Al mismo tiempo, se estimula el receptor NMDA cuyo canal se abre y el Ca++ se precipita al interior de la neurona. El calcio activa una o varias proteino kinasas, que son enzimas que fosforilizan proteínas. Aparentemente, una proteino kinasa calcio dependiente y una proteino kinasa calmoludino dependiente (la calmoludina se activa cuando se liga al calcio) se estimulan y determinan cambios protéicos estructurales, que originan la LTP por diversos mecanismos uno de los cuales sería volver los receptores postsinápticos mas sensibles al neurotransmisor. Se piensa que ta entrada de calcio al interior de la neurona activa una proteino kinasa porque la administración de inhibidores de proteino kinasas (levendustin A y genistein) bloquean la inducción de la LTP (ver Fidia Research Foundation, 1991). Esta primera proteino-kinasa activaría a su vez otra(s) proteino kinasas que amplificarían aún mas la respuesta al glutamato. Una de estas proteino kinasas sería la MAP kinasa ("mitogen activated protein kinase"). Esta hipótesis parte del principio que la LTP se debe a un fenómeno postsináptico, que determina una mayor sensibilidad de los receptores postsinápticos al neurotransmisor, de tal manera que cuando se estimula el elemento presináptico el potencial postsináptico es de mayor intensidad que antes del aprendizaje. Como hemos señalado más arriba, recientemente 


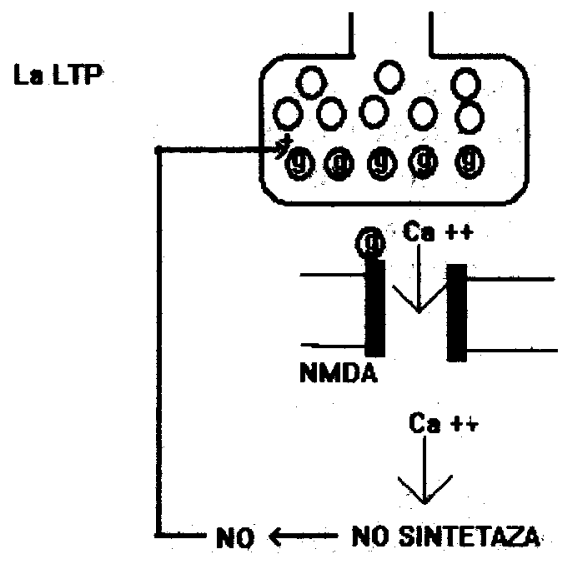

Figura 3

El glutamato (g) estimula un receptor NMDA que se abre y deja ingresar calcio $\left(\mathrm{Ca}^{++}\right)$estimulando la enzima NO sintetaza. Se produce óxido nítrico (NO) que activa retrógradamente el botón presináptico. Esta activación détermina una mayor producción de glutamato por el botón.

se han aportado pruebas que la LTP se debe a un fenómeno presináptico que llevaría a una mayor secreción de neurotransmisor con un consiguiente refuerzo. del efecto postsináptico (es decir un potencial postsináptico mas intenso). En este caso se postula que un mensajero retrógado lleva el mensaje de la neurona postsináptica a la presináptica modificándola y determinando la mayor secreción de quantas de neurotransmisor. Numerosos grupos como Garthwaite et al. de la Universidad de Liverpool (1989), Bohme et al del Centro de Investigaciones de Vitry Alfortwille en Vitry sur Seine (1991), Madison y Schuman de Stanford (1991), Kandel et al. de la Universidad de Columbia (1991), Chapman, Haley y Wilcox de la universidad de Minnessota (1991) (ver Barinaga, 1991), han postulado que el transmisor retrógrado podría ser el óxido nítrico (NO) aportando algunas pruebas experimentales a esta idea. Una posibilidad podría ser que la liberación de glutamato por el elemento presináptico estimularía los receptores NMDA, los que dejarían entrar calcio en la neurona postsináptica. El calcio iniciaría una serie de procesos (similares a los descritos más arriba); que conducirían a la activación de la enzima óxido nítrico sintetaza, la que produce NO a partir de arginina. El NO difundiría libremente a través de la membrana y determinaría cambios presinápticos (mediados por la guanil ciclasa y el GMP cíclico) conducentes a la liberación de mayores cantidades del neurotransmisor al producirse una nueva estimulación del circuito (el que se hallaría en estado de facilitación). Esta facilitación no es otra cosa que una LTP. Esta hipótesis tiene 
de atractivo el hecho que hace intervenir tanto al glutamato y a su receptor NMDA, así como a un mecanismo presináptico y está en concordancia con los diferentes estudios que se han hecho sobre la LTP.

Todo aprendizaje requiere la posibilidad del olvido para mejorarlo o ampliarlo o porque puede demostrarse que es incorrecto. Una estructura implicada en el aprendizaje requiere por lo tarito de mecanismos que permitan el olvido o en términos "Hebbianos" la desactivación de un circuito es decir de la LTP. En el hipocampo se ha demostrado también la existencia de un mecanismo sináptico llamado la LTD (Mulkey, Herron y Malenka, 1993) que se produce a nivel de las mismas sinapsis que la LTP pero en sentido inverso (depresión de una sinapsis que se vuelve menos efectiva). La LTD se produciría cuando por una sinapsis glutamatérgica llega un tren de impulsos de baja frecuencia $(1 \mathrm{HZ}$, por ejemplo) que estimula un receptor NMDA. El ingreso de bajas cantidades de $\mathrm{Ca}++$ (contrariamente a lo que ocurriría en la LTP en que ingresan elevadas cantidades de $\mathrm{Ca}++$ ) desencadenaría una serie de eventos que conducirían a una LTD. El más importante de los cuales consiste en la activación de fosfatasas (enzimas que substraen fósforo de otras proteínas por lo que actúan en sentido inverso a las proteino kinasas). Estas fosfatasas, al inactivar una o varias proteínas, conducirían a la depresión de la transmisión sináptica.

Para comprender la acción del hipocampo es necesario tener en cuenta la amplísima información que puede procesar proveniente de diferentes regiones corticales y que puede ejercer efectos muy variados sobre esas mismas regiones corticales y el diencéfalo. Pensamos, en la actualidad, que el cerebro es un órgano especializado en el procesamiento de información: cada neurona, cada circuito interneuronal dentro de la misma área y los distintos circuitos areales interconectados constituyen una complejísima red procesadora de información. Se llama información a una señal, mensaje, comunicación o concepto codificables. Desde el punto de vista de la psicología cognitiva, la información que codifica el cerebro es fundamentalmente de dos categorías: proposiciones, que corresponden a las representaciones lingüísticas e imágenes que corresponden a las representaciones perceptivas (Stillings, Feinstein, Garfiel et al. 1987). Er concepto de procesamiento se refiere a las operaciones (algoritmos) que pueden hacerse con esta información y que son realizadas por un elemento procesador. Por ejemplo, en la multiplicación de 24 × 32 hay que seguir una regla (algoritmo) para llegar al resultado final correcto. Lós números 24 y 32 constituyen la información, mientras que el atgoritmo que permite multiplicarlos es el procesamiento. Se puede hipotetizar que en el cerebro existen regiones que se encargan de adquirir o almacenar la información y regiones que se encargan de procesarla. Las zonas cerebrales en relación con la adquisición o el almacenamiento de la información estarían representadas por lo lóbulos parietal, occipital y temporal de ambos 
hemisferios, mientras que el procesador estaría encarnado por el lóbulo prefrontal. La ejecución del comportamiento quedaría a cargo de las estructuras motoras del lobulo frontal y subcorticales (ganglios basales, cerebelo, motoneuronas, etc.) y de la zona del lenguaje, del hemisferio izquierdo, en el caso del comportamiento lingüístico.

Una teoría neurológica de la memoria que tome en cuenta las ciencias cognitivas del procesamiento de la información hace de la memoria un fenómeno múltiple. En efecto, aunque subjetivamente la memoria se presenta como un hecho único, el análisis neuropsicológico y el biológico lleva a considerar que en ella participan diversos mecanismos que difieren por sus procesos básicos y por los lugares del cerebro donde son realizados. Por lo menos tenemos que considerar tres aspectos: el almacenamiento por algunas semanas o meses en el hipocampo, el almacenamiento definitivo en el neocortex (ambos son vividos subjetivamente como una memoria a largo plazo) y el uso de los datos almacenados para su procesamiento en una memoria temporal que llamaremos la memoria activa ("working memory").

Recientemente, Wilson y McNaughton (1993) y Einchembaum (1993), han aportado luces sobre la función del hipocampo. Los primeros, por un estudio experimental y el segundo, con una interpretación teórica sobre los conjuntos neuronales. Sin entrar en los detalles que serían muy complicados trataré de exponer sus conclusiones lo más fielmente posible. Desde hace un tiempo se sabe que en la rata y otros roedores, el hipocampo contiene neuronas que han sido llamadas "neuronas de lugar" porque aumentan su actividad cuando el animal se encuentra en un lugar determinado, como si furesen capaces de interiorizar una localización topográfica externa. Wilson y McNaughton (1993) han estudiado por medio de registros unitarios la actividad de muchas células hipocámpicas $(73$ a 148) de la rata mientras el animal exploraba y aprendía un laberinto. Pudieron demostrar, de esta manera, que la actividad de varias células hipocámpicas al mismo tiempo codificaba mucho mejor la posición del animal y la topografía de un punto determinado del medio ambiente que la actividad de una sola célula. Este hallazgo va bien con lo que conocemos del hipocampo en el sentido que sus células pueden establecer rápidamente circuitos duraderos entre varias de ellas por medio de la LTP. Las neuronas interconectadas por un circuito, cuyas sinapsis están facilitadas, forman una red neuronal. El experimento descrito más arriba demuestra que el código hipocámpico es mas exacto cuando se hace en un ensamble o red neuronal. En el hombre la codificación no se refiere solamente al espacio sino que comprende otros conceptos como seres humanos, vivencias, proposiciones o representaciones lingüísticas, imágenes, conocimientos escolares y universitarios, etc. 
Como ya hemos señalado, el hipocampo es una estructura privilegiada para recibir información al mismo tiempo, o casi al mismo tiempo, de numerosas regiones disímilés del cerebro (Figura 4 ). Su función sería la de codificar relaciones entre actividades llevadas a cabo en diferentes áreas cerebrales. Por ejemplo, la visita guiada de una ciudad implica la actividad de varias regiones corticales: visuales, auditivas, sensitivo motoras. Las distintas regiones cerebrales van generando mi percepción de la ciudad en la que se asocian imágenes visuales, información de tipo lingüístico, conocimientos históricos, apreciación artística, sentimiento de agrado o desagrado, etc. Cada uno de estos rasgos constituyen la imagen que uno se forma de la ciudad y se procesan en lugares diferentes de la corteza. Cada uno de estos lugares informa sobre su actividad en curso al hipocampo, en el que se forma una red neural que "guarda" un código que corresponde a la actividad de todas las regiones que participaron en la experiencia de la ciudad. El recuerdo está representado físiológicamente por este código conservado en el hipocampo. Cuando es activado desencadena el funcionamiento de las diferentes redes neuronales que corresponden a la vivencia de la ciudad.

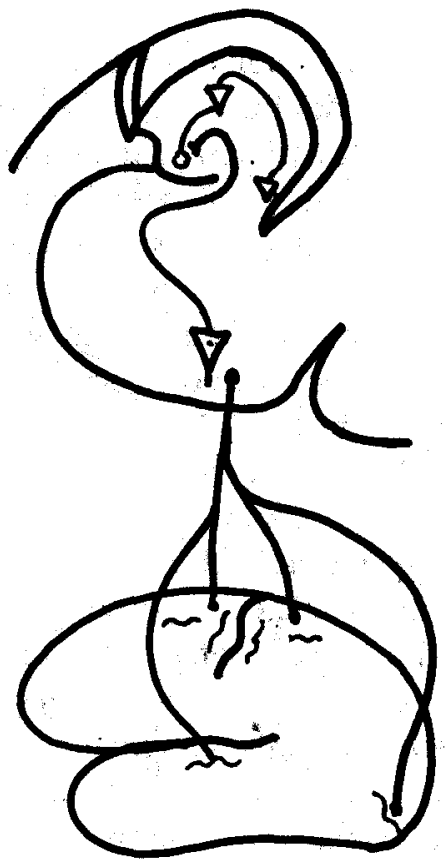

Figura 4

Esquema que muestra la función hipocámpica. La percepción de una ciudad cuando la visitamos desencadena actividades en una serie de neuronas localizadas en las áreas cognitivas: visuales, verbales y auditivas, kinestésicas; motoras El concepto (o la imagen) de la ciudad corresponde a la actividad de determinadas neuronas en esas regiones. El hipocampo guardaría bajo la forma de un cicuito el código correspondiente para poner en actividad las mismạs neuronas en las áreas correspondientes, permitiendo así que surja el recuerdo de la ciudad. 
Se puede resumir la función hipocámpica de la siguiente manera: (1) El hipocampo es indispensable en el aprendizaje (memoria explícita) y retiene "los recuerdos" por algunas semanas, como lo demuestran los enfermos con destrucción bilateral de ambos hipocampos. (2) Existe un predominio por la codificación lingüística en el hipocampo izquierdo y por la visuo espacial en el derecho (Milner, 1990). (3) La codificación hipocámpica se hace fundamentalmente en redes neuronales que se forman por el reforzamiento de las sinapsis entre las neuronas que constituyen una red. (4) Una determinada sinapsis se "refuerza" por medio de la LTP. (5) El hipocampo tiene conexiones con todo el parénquima cerebral, por lo que puede recibir información y enviarla a todas las áreas con las que está conectado. Esta situación lo pone en un lugar privilegiado para codificar relaciones entre las actividades que se llevan a cabo en diferentes partes de la corteza cerebral. (6) Al cabo de cierto tiempo, la traza hipocámpica de un recuerdo es transferida por un mecanismo no bien conocido a otras regiones del neocortex para su almacenamiento definitivo. La red neuronal hipocámpica deja entonces de funcionar. (7) Se ha descrito otro fenómeno en el hipocampo, la LTD, que puede explicar la desaparición de la traza hipocámpica.

Los recuerdos deben poder ser utilizados en cualquier momento para lo que se necesita que se activen y se hallen disponibles para que el procesador pueda usarlos. La estructura en la que se almacenan temporalmente, mientras se encuentran a disposición del procesador, se llama la memoria activa y se encuentra en el lóbulo prefrontal.

Estudios recientes demuestran que las neuronas del lóbulo prefrontal del mono intervienen en funciones cognitivas como la memoria activa ("working memory"). La memoria activa es un concepto que se origina en la psicología cognitiva y en las ciencias del procesamiento de la información. Se conceptualiza, desde el punto de vista de las neurociencias, como una función cerebral que permite retener datos (la información) por un corto tiempo mientras se ejecutan procesos con esos datos. Esa información puede provenir del medio ambiente a través de la información sensitivo sensorial o de la memoria a largo plazo. Su condición natural es la de desvanecerse rápiđamente, pudiendo sólo mantenerse por medio de la intervención de la atención. Por ejemplo, una actividad aritmética (como sumar el resultado de $2+2$ al resultado de $10-3$ ) o jugar un partida de ajedrez, o construir una frase (Goldman-Rakic, 1992). La memoria activa ha sido llamada "la pizarra de la mente"; su capacidad es limitada. Algunos la describen como compuesta de tres partes: una central y dos periféricas. Estas últimas están representadas por un componente visual para las imágenes visuales y uno auditivo para las imágenes audio linguisticas. La región central utilizaría la información mantenida en los componentes periféricos para procesarlos. Este sistema es inespecífico en el sentido que puede manipular datos que varían en el tiempo 
de acuerdo a la actividad en curso (posición de un objeto, forma del objeto, fonema, palabra, frase, símbolo aritmético, cantidad, etc). Wilson et al (1993) han estudiado, en el mono, la participación del lóbulo prefrontal en la memoria activa visual. Han demostrado, mediante el uso de técnicas de registro de la actividad neuronal al tiempo que se presentan objetos por el canal visual, que la corteza latẻral dorsal (superior) del lóbulo prefrontal participa en la retención de la posición espacial del objeto una vez que este ha desaparecido del campo visual. Por su lado, la corteza lateral inferior de este mismo lóbulo es necesaria para el "recuerdo" de la forma del objeto (hay neuronas que aumentan su actividad cuando el mono está recordando un círculo roja pero no cuando evoca un cuadrado verde). De esta manera, se mantendría "en la conciencia" los atributos de un objeto que ya desapareció del campo visual pero sobre el que todavía tienen que realizarse operaciones cognitivas (por ejemplo, su búsqueda en un matorral). Las destrucciones del lóbulo prefrontal en el mono conducen a alteraciones en las pruebas de respuesta retardada, en las que una respuesta es exigida con retardo y no inmediatamente. Este tipo de pruebas exploran la memoria activa (Goldman-Rakic 1992). Un ejemplo es la prueba diseñada por Funashabi, Bruce y Goldman-Rakic en la Universidad de Yale (Goldman-Rakic 1992): se enseña a un mono a fijar un punto situado en el centro de un ecran; luego en uno de los ocho lugares del ecran se proyecta un cuadrado por algunos instantes. Cuatro a seis segundos después que ha desaparecido el cuadrado desaparece el punto central, lo que le indica al animal que debe dirigir la mirada hacia el lugar en que apareció el cuadrado. Estos autores han demostrado que en el lóbulo prefrontal se activa una neurona desde la desaparición del cuadrado, hasta que el animal dirige la mirada en su dirección. Luego la actividad cèsa en la neurona prefrontal. Se piensa que la función de esta neurona prefrontal es conservar la posición del objeto durante un tiempo. Si el animal se distrae la actividad neuronal desaparece y el mono es incapaz de dirigir la mirada apropiadamente.

En el mono, la región del surco principal del lóbulo prefrontal se halla conectada a una serie de regiones corticales y subcorticales. Es una zona que forma parte de una compleja red de conexiones en las que participan las principałes regiones límbicas, sensitivo sensoriales y motoras. Por medio de esta red el lóbulo prefrontal se halla en la capacidad de organizar la información que debe fluir a través de él. Según Goldman-Rakic (1992) funcionaría como un intermediario entre la memoria y la acción. Para esta autora, el lóbulo prefrontal estaría constituido por diferentes dominios de memoria cada uno de los cuales se especializaría en la codificación de un tipo especial de información, tal como la localización de un objeto, sus características (forma, color, tamaño) y adicionalmente; en los humanos, conocimientos semánticos y matemáticos. Estudios, usando registros con la tomografía por emisión de positrones (PET), 
han puesto en evidencia una actividad en el lóbulo prefrontal del hombre cuando se somete voluntarios a pruebas que requieren que el sujeto retenga una lista de palabras o que enuncie un verbo determinado cuando oye un nombre. Para Goldman-Rakic (1992) hay una creciente evidencia experimental que muestra que las aferencias dopaminérgicas constituyen uno de los sistemas neuroquímicos más importantes en la regulación de la memoria activa.

La memoria que se presenta a la introspección como una función unitaria es, en realidad, como puede desprenderse de lo expuesto, una multiplicidad de funciones, cada una de las cuales se realiza en regiones especializadas y distintas del sistema nervioso central. Los enormes avances que se han obtenido en su estudio son, esperamos, los prolegómenos de la aparición de sustancias que la mejoren. Con ello el hombre habrá logrado uno de sus sueños mas codiciados.

\section{Referencias}

Amaral, D.G. (1990). Cortical afferents of the primate hippocampal formation. En Squire L.R., M. Mishkin y A. Shimamura (eds). Learning and Memory. Discussions in Neurosience, VI, 3-4; 17-20.

Barinaga, M. (1991). The tyde of memory, turning. Science, 248, 1603-1605. Damazio, A. (1992). Brain and Language. Sientific American, 267, 63-71.

Eichembaum, H. (1993). Thinking about cell assemblies. Science, 261, 993-994. Fidia Research Foundation (1991). Neurosciences Facts, 2, 21.

Goldman-Rakic P. (1992). Working memory and the mind. Scientific American, 267, 73-79.

Kandel, E.R. (1992). La Memoire. Conferencia pronunciada en la Sociedad de Neurología Francesa, París.

Kandel, E.R. y R.D., Hawkins (1992). The biological basis of learning and individuality. Scientific American, 267, 53-60.

Milner, B. (1979). Memoria y las regiones temporales mediales del cerebro. En J. Grimberg-Zylberbaum (ed.) Bases psicofisiológicas de la memoria y' el aprendizaje; 67-91. México: Trillas.

Milner, B. (1974). Hemispheric specialization: scope and limits. En FO Schmitt y FG Worden (eds.) The Neurosciences: Third study program. 78-87. Cambridge, Massachusetts: The MIT Press.

Mulkey, R.M. C.E. Herron y R.C. Malenka (1993). Protein phosphatases in hippocampal long term depression. Science, 261, 1051-1055.

Penfield, W. (1975). El misterio de la mente: estudio crítico de la conciencia y el cerebro humano. Madrid: Pirámide.

Squire, L.R., M. Mishkin y A. Shimamuru eds. (1990). Learning and Memory. Discussions in Neuroscience, VI, 3 y 4. 
Squire, L.R. y S. Zola-Morgan (1991). The medial temporal lobe memory system. Science, 253, 1380-1386.

Stillings. N.A., Feinstein, M.H., Garfield, J.L., Rissland, E.L., Rosenbaum, D.A. Weisler, S.E. and Baker-Ward, L. (1987). Cognitive Science: An Introduction. Cambridge, Massachusetts: The MIT Press.

Wilson, M.A. y B.L. McNaugton (1993). Dynamics of hippocampal ensemble code for space. Science, 261, 1055-1058. 